\title{
Risk Characteristics of New Technology Operation
}

\section{Jianhui Kong1,2 Fengying Zhang ${ }^{3}$ Yiwu Zhou $^{4}$ Qian Qian $^{1}$ Xiaofeng Xie $^{1}$ Zongfang Zhou ${ }^{1}$}

${ }^{1}$ School of economics and management, university of electronic science and technology, Chengdu; ${ }^{2}$ Southwest university of nationalities law school, Chengdu; ${ }^{3}$ School of nursing, sichuan university, Chengdu; ${ }^{4}$ Suzhou huiyutong data technology co., LTD., Suzhou

\begin{abstract}
This paper analyzes the risk factors and risk characteristics of new technology operation. Due to the overall risk of the operation of the new technology to a large extent depends on the operating carrier, technology, market and service, therefore, this article will from the operating carrier, technology, market and service point of view, that is, from the perspective of endogenous risk (not systemic risk) to discuss some key risk factors affect the success or failure of the new technology operation. These risk factors is not only a new technology of operation risk sources, and depict the new technology to the four types of risk to the operating characteristics, namely, credit risk, technology innovation risk, market risk and technical risk characteristics.
\end{abstract}

\section{Keywords}

New Technology (NT); New Technology Operations (NTO); Operations Risk; Risk Characteristics

\section{新技术运营的风险特征*}

\section{孔建会 1,2 张风英 ${ }^{3}$ 周一惁 ${ }^{4}$ 钱茜 ${ }^{1}$ 谢小风 ${ }^{1}$ 周宗放 ${ }^{1}$}

\section{1 电子科技大学经管学院, 成都 $611731{ }^{2}$ 西南民族大学法学院, 成都 610041 ; ${ }^{3}$ 四川大学护理学院, 成都 $610041 ;{ }^{4}$ 苏州汇誉通数据科技有限公司, 苏州}

215123

摘要：本文针对新技术运营的风险要素和风险特征展开分析。由于新技术运营的总体风险在 很大程度上依赖于运营载体、技术、市场和服务，因此，本文将从运营载体、技术、市场和 服务的角度，即从内生性风险（非系统性风险）的角度来讨论影响新技术运营成败的一些关 键性风险要素。这些风险要素不仅是新技术运营的风险来源, 而且刻画了新技术运营面临的 四类风险特征，即信用风险、技术创新风险、市场风险和技术服务风险特征。

关键词：新技术；新技术运营；运营风险；风险特征

\footnotetext{
*国家自然科学基金资助项目（71271043、71473031）。
} 


\section{1. 引言}

随着科学技术的进步，互联网、信息 与电子、人工智能、生物医学、新材料、 新能源、大数 据 等新技术 ( New Technology, NT) 已经将技术创新活动置 于当今我国科技革命的最前沿。基于中国 的国情，本文对相关概念界定如下：“新 技术” 是指应用现代科学技术的基本原理 和方法, 自主研制且具有技术创新特征的 技术（含专利技术）；新技术运营（New Technology Operations，NTO）是指新技 术运营的载体（企业）依托新技术所开展 的相关经营活动, 反映了新技术转化的商 业化过程; 新技术的载体称为新技术运营 企业（New Technology Operations Enterprise, NTOE），这类企业的特征是 依托某一个或某一些新技术 (包括由多个 非独立新技术集成的复杂技术），以技术 创新、经营、产品生产和销售以及售后服 务为一体的企业; 新技术运营的产品

( New Technology Operations Products, NTOP）是指依托新技术而生产的产品或 服务, 这些产品或服务具有技术创新和独 特性。

本文所讨论的新技术主要指民用的自 主创新类技术，这些新技术通常具有可观 的市场前景和商业价值, 但也存在不可小 觑的运营风险。由于新技术的运营无论在 技术创新层面, 还是在新产品的生产、销 售和服务等环节均存在较大的风险, 这些 风险大多属于 “内生性风险”，是导致新 技术运营失败的主要风险。所谓 “内生性 风险” 是指新技术运营者能够通过采取适 当措施加以控制和管理的风险。因此, 本 文认为内生性风险是新技术运营面临的主 要风险特征, 不仅构成了新技术运营的风 险链, 而且是识别新技术运营风险的重 点。目前, 国内外相关研究不多, 更鲜见 针对新技术运营风险展开的研究 ${ }^{[1-2]}$ 。

\section{2. 新技术运营的风险要素}

根据新技术运营的特点可知, 新技术 运营的总体风险在很大程度上依赖于运营 的载体、技术、市场和服务所形成的新技
术、市场和服务的角度来看, 关系到新技 术运营成败的决定性风险要素主要包括以 下四类：(1) 新技术运营企业的信用风险; (2) 由技术约束导致的新技术运营的技术风 险; (3) 由市场约束导致的新技术运营产品 的市场风险; (4) 新技术运营的技术服务保 障能力不足导致的风险。以下将分别对上 述风险要素进行分析。

\section{1. 来自新技术运营企业的信用风险}

新技术行业的蓬勃发展, 大量的企业 开始涉足于新技术的运营。由于新技术运 营企业的扩张能力强, 对资金的持续需求 往往较大且十分急迫, 因此, 进入该行业 的企业往往需要巨大的资金投入。新技术 运营企业的信用风险反映了运营企业的履 约和融资能力, 运营企业的信用风险成为 新技术运营能否成功的关键要素之一。事 实上, 信用风险不仅反映了企业的财务状 况和融资能力, 而且也反映了企业的生存 条件和成长环境, 换言之, 在信用经济环 境中，信用差的企业将寸步难行。

从融资渠道来看, 信用优良的新技术 运营企业不仅可以借助于政府财政资金的 支持, 而且也更加容易获得金融机构或投 资者的资金支持。事实上，由于新技术运 营的潜在丰厚收益, 且投资风险具有一定 的可承受性, 因此, 得到投资者和金融机 构的青崃。目前, 不少商业银行、各类投 融资机构、企事业单位等都与信用优良的 新技术运营企业建立了各种各样的借贷或 交易关系, 换言之, 信用优良的新技术运 营企业具有更小的资金约束。

综上所述, 由于企业的信用风险水平 直接影响到企业的融资能力, 而企业的融 资能力又与企业的信用风险密切相关, 因 此, 新技术运营企业的信用风险是决定新 技术运营成败的关键要素。换言之, 新技 术运营企业的信用风险是新技术运营面临 的关键风险要素, 信用风险大的企业将被 “一票否决”。

\section{2. 由技术约束导致的技术创新风险}

技术的先进性、独创性、成熟度或可 靠性以及安全性是评价技术创新水平的关 


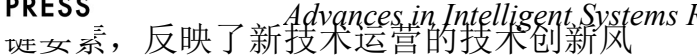
险（见表 1）。

表 1 ：新技术运营的技术创新评价要素

\begin{tabular}{|c|c|}
\hline 评价要素 & 内 涵 \\
\hline 技术的先进性 & 与现有技术差异及先进程度 \\
\hline 技术的独创性 & 独创功能及实现程度 \\
\hline $\begin{array}{c}\text { 技术的成熟度或可靠 } \\
\text { 性 }\end{array}$ & $\begin{array}{c}\text { 技术运营的可实现性和协调 } \\
\text { 性 }\end{array}$ \\
\hline 技术的安全性 & 技术运营各环节的便利性 \\
\hline 技术的可操作性 & $\begin{array}{c}\text { 技术本身与周围环境的协调 } \\
\text { 性 }\end{array}$ \\
\hline 可维护性 & 维护维修技术的可实现性 \\
\hline 防模仿性 & 技术的含量 \\
\hline
\end{tabular}

从技术创新风险的角度来看，技术创 新风险主要源于技术的不成熟和不确定 性，在新技术的研发和运营阶段都面临较 大的技术创新风险。由新技术的不成熟所 导致的技术创新风险, 称为新技术运营的 内部 “技术约束”。由新技术运营的内部 “技术约束” 所导致的技术创新风险不仅 反映在新技术的研发阶段, 而且很大部分 反映在新技术的运营阶段, 例如, 从我国 互联网发展历程来看, 当互联网技术处于 初始发展阶段时, 由于技术的约束, 当时 的 ISP 技术很快被其他互联网技术所替 代，导致当时采用 ISP 技术的互联网企业 面临极大的技术风险。

在新技术的运营阶段, 除了来自新技 术的技术约束外，还受制于其他相关技术 所导致的 “技术约束” ，称其为新技术运 营的外部“技术约束”。这种来自于外 部 “技术约束” 所导致的技术创新风险通 常使得新技术运营的初级产品比较单一。 例如, 互联网技术在我国的运营初期, 人 们直接的需求是能够上网, 几乎所有的 ISP 技术 (互联网接入技术) 都提供相同 的产品。其必然的结果是：采用该技术的 一大批互联网企业争夺一个较小的市场 [3]，最终导致一些互联网企业被淘汰。

“技术约束” 还常常导致先进入该领 域的企业较后进入的企业面临更大的技术 创新风险。事实上, 由于技术的约束, 先 进入的企业常常具有显著的同质化特点, 但是随着技术的成熟和进步, 后进入的企 业会规避这些技术缺陷, 从而降低了技术 创新的风险。综上所述, 新技术运营的技
染创新左入险是新技术运营阶段所面临的重 要风险要素。

\section{3. 由市场环境约束造成的市场风险}

新技术运营的市场风险主要来自于新 产品的商业化阶段: 一方面, 新技术运营 产品 ( New Technology Operations Product, NTOP) 面临较大的市场接受风 险; 另一方面, 由于人们认知上的缺乏, 使得在开拓新产品市场前, 率先研发或运 营 NTOP 的企业将承担向潜在消费者普及 新产品的成本, 称该性质为 NTOP 的外部 性。

显然, NTOP 的市场接受风险和外部 性导致了 NTOP 的 “市场约束”，“市场 约束” 是新技术运营过程面临的主要市场 风险。例如, 在互联网技术在运营的初始 阶段, “市场约束” 尤其突出, 先采用互 联网技术的企业花费了很大的成本, 才让 消费者逐渐认识互联网。随着互联网技术 的不断成熟和完善, 互联网的服务内容越 来越丰富多彩、价格也越来越低廉, “市 场约束” 随之放宽。先研发或采用 ISP 技 术的企业如果不及时更新产品和经营理 念，因势利导，则可能失去原来的客户， 最终失去市场。综上所述, 新技术运营的 市场风险是新技术运营所面临的主要且复 杂的风险要素。

\section{4. 技术服务保障能力不足导致的风险}

服务代理商制度不仅有利于更好地满 足客户的需求, 而且有助于将 NTOP 更快 的推向市场。对 NTOP 而言, 由于 NTOP 的技术专有性和市场特征, 较大型的新技 术运营企业一般选择服务总代理的形式， 并且给予技术服务代理商相应的权限 ${ }^{[4]}$ 。 事实上, 一方面, 由于新技术运营的技术 约束性, NTOP 的维修维护技术和成本非 一般服务代理商可以承担; 另一方面, 由 于 NTOP 的市场约束性, NTOP 的技术服 务商还应该具有市场推广的职能。因此, NTOP 的技术服务代理商不仅应该具有对 NTOP 维修维护代理的技术职能, 而且还 应该兼备 NTOP 的销售和备品备件采购等 代理职能。因此, 新技术运营企业所选择 的技术服务代理商不仅应该具有相应的技 
小片分能力, 而且应该具有较强的综合实 力。这类技术服务代理商通常是新技术运 营企业的重要战略合作伙伴。显然，如果 技术服务代理很弱, 则 NTOP 可能面临由 于服务代理不到位而失去客户和市场, 最 终导致新技术运营的失败。因此，技术服 务保障能力的不足是新技术运营所面临的 又一风险要素。

\section{3. 新技术运营的风险特征}

新技术运营涉及的风险众多，大致可 以划分为 “外生性风险” 和 “内生性风 险”。其中，外生性风险（系统性风险） 大多是运营者难以控制的风险，并且与新 技术运营的成败虽然具有相关性但并不是 直接相关的; 而内生性风险（非系统性风 险）大多是与新技术运营的成败直接相关 的风险，并且运营者可以通过提升管理、 技术创新、市场营销和技术服务的水平来 控制和降低这类风险。如果风险既与内生 性风险有关，又与外生性风险有关，而且 外生性风险占主导地位, 本文则称这类风 险为 “拟外生性风险”，运营者只能控制 其中的内生性风险部分。因此, 从新技术 运营的角度来看, 内生性风险是相对容易 控制的风险，表现了新技术运营的主要风 险特征。基于此, 本文从内生性风险的角 度, 即从运营载体、技术、市场和服务的 角度, 来讨论与新技术运营的成败直接相 关的风险特征。依据内生性风险的内涵, 新技术运营的风险可以大致归纳为信用风 险、技术创新风险、市场风险和技术服务 风险等四类。由于管理风险贯穿于该四类 风险之中, 本文不再单独列出。上述四类 风险分别具有不同的风险特征, 以下将分 别进行分析。

\section{1. 信用风险 (CR) 特征}

本文所指的新技术运营的信用风险 是指新技术运营的载体, 即新技术运营企 业的信用风险。新技术运营企业的信用风 险不仅反映了新技术运营过程中所面临的 履约风险, 而且也反映了新技术运营企业 的财务风险和融资能力, 同时还会影响到 NTOP 的市场销售水平乃至企业的生存和 发展。因此, 新技术运营的信用风险是新
技条运营的重要风险特征之一，可以用新 技术运营企业的信用风险来体现, 信用差 的企业将被一票否决, 即信用风险大的企 业没有运营新技术的资格。

\section{2. 技术创新风险（TIR）特征}

技术研发阶段的风险一般可以用技术 成熟度（Technology Readiness）来衡量。 技术成熟度的概念最早由美国航空航天局

(NASA) 于 20 世纪 70 年代提出， 2011 年, 美国国防部颁布了《国防部技术成熟 度评价指南》的最终版本, 主要针对应用 新技术的研制, 强调从技术开发的完备性 及验证的充分性两个方面, 从技术原理、 概念、设想、实验环境、模拟环境、实际 环境到通过技术检验、技术研制成功等不 同的技术发展过程, 将技术成熟度等级

( Technology Readiness Levels, TRL) 划 分为 9 个等级 ${ }^{[5]}$ 。从技术成熟度的本质来 看, 其客观反映了技术的发展规律和技术 创新过程中所面临的风险 ${ }^{[6]}$ 。因此, 对新 技术而言, 可以认为技术创新能力越强, 技术的成熟度越高, 新技术运营的技术创 新风险越小。

Handerson 和 Clark（1990）认为技术 创新可以分成四类 ${ }^{[7]}$ : 渐进性创新、模块 性创新、结构性创新和根本性创新。技术 创新的成败不仅依赖于技术本身, 而且还 依赖于市场的可接受性, 因此, 技术创新 同时包括了技术和市场两个方面。一般而 言, 技术创新机制是提升新技术运营技术 水平的根本保障。技术创新机制一方面给 新技术运营企业的研发及经营带来了竞争 优势和更加广阔的发展机会, 同时又给新 技术运营带来较大的技术创新风险。事实 上, 一旦技术创新风险加大，外部投资者 可能采取延迟投资或缩减投资, 甚至放弃 或转移投资等多种行为。显然, 技术创新 能力越低, 新技术运营所面临的技术创新 风险越大, 因此, 技术创新能力刻画了新 技术运营的技术创新风险特征。

\section{3. 市场风险（MR）特征}

新技术运营的市场风险主要源于新技 术运营产品（NTOP）的市场效益, NTOP 的市场效益越高, 市场风险越小。 


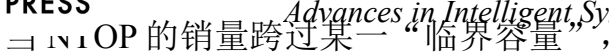
潜在采用者愿意为之支付更高价格时, NTOP 的市场效益就会成倍增加。随着 NTOP 的均摊成本快速下降, 利润和市场 快速扩张, 形成所谓 “赢者通吃” 的现 象, 从而获得竞争性垄断地位。因此, 新 技术的运营企业通常会采用 “市场比利润 更重要” 的原则, 早期可能以低于成本的 价格出售或㻌销给潜在采用者, 以求未来 的市场。换言之, NTOP 的市场效益具有 “盈利滞后” 的特性。

NTOP 大致可划分为 “改进型” 、 “突破型” 和 “早熟型” 等几种类型。所 谓 “改进型” 新技术运营产品一般指原有 产品的升级换代产品, 当其产品销量跨过 某一临界容量时，市场呈集群性增长; 所 谓 “突破型” 新技术运营产品是指产品销 量一旦突破某一临界点, 由正反馈原理, 该产品呈现爆炸性、集群性的增长; 所谓 “早熟型” 新技术运营产品是指对于那些 技术的过于超前，其生存的市场条件尚未 形成或不稳定的新技术产品, 通常这类产 品会因为市场销量不能跨过某一临界容量 而失败。由于 NTOP 的更新周期正在快速 缩短, 一代 NTOP 市场可能刚刚形成规 模, 就已经开始分化, 呈现易逝性产品的 特性。因此, 常常出现多代 NTOP 市场并 存的局面。综上所述, NTOP 市场具有多 种特性, 对其市场效益和市场风险的分析 异常复杂。由于 NTOP 采用者的空间分布 及其动态变化过程是体现新技术运营的市 场效益和市场风险的重要依据, 因此, 可 以根据 NTOP 采用者空间分布的动态变化 特征来刻画新技术运营的市场风险特征。

\section{4. 技术服务风险（TSR）特征}

进入 21 世纪以来, 以生产为重心的 传统经营观点正在发生改变, 服务越来越 受到厂商的重视。目前, 服务创造价值的 经营理念已经在我国许多行业或厂商得到 了体现。另一方面, 服务是有成本的, 只 有当服务的成本小于服务所创造的价值 时, 厂商才会从所提供的服务中获得收 益。

在当前的科技创新时代, NTOP 面临 变化多端的市场环境和技术环境, 对新技 术运营企业的技术创新和管理决策能力都

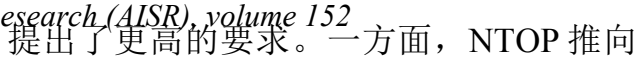
市场之后, 由于技术不完善或者产品使用 不当, 都可能导致 NTOP 的效能不稳定或 者发生故障; 另一方面, 新技术运营企业 都希望能够将自身有限的精力和资源投入 到新技术运营的研发、生产和经营上, 进 一步巩固和发展自身的核心业务, 因此, 在客观上产生了对技术服务代理的需求。

技术服务质量对新技术运营的成败和 可持续发展均具有重要作用。由于技术服 务代理是接近用户的最前沿, 是能否满足 用户需求的关键所在。但不同的技术服务 代理商在服务质量上有很大差别, 如果技 术服务代理商选择不当, 不仅可能导致新 技术运营的失败, 并且可能给新技术运营 企业带来很大的损失甚至遭受毁灭性的打 击。因此, 新技术运营企业必须非常谨慎 地选择技术服务代理商。由于技术服务代 理商的质量直接反映了新技术运营的技术 服务水平, 因此, 本文用技术服务代理的 质量来刻画新技术运营的技术服务风险特 征, 根据技术服务代理商的质量高低来测 度新技术运营技术服务风险的大小。

\section{4. 新技术运营的风险特征模型}

空间分析方法是一类常用的动态分析 方法, 由于具有可视化的特征, 已被广泛 地应用于各类风险分析中 ${ }^{[8-9]}$ 。在由新技 术运营的四类风险特征 (信用风险、技术 创新风险、市场风险和技术服务风险）形 成的四维空间中, 本文构造出如下图 1 所 示的新技术运营的风险特征模型。其中， 新技术运营的信用风险特征轴 (即 CR 轴）反映了新技术运营企业的信用风险水 平，该轴上取值越大，信用风险越大; MR 轴为市场风险特征轴, MR 轴上的取 值可以用于测度新技术运营产品的市场风 险, 该轴上取值越大, 市场风险越大; 技 术创新风险轴 TIR 反映了新技术运营的技 术风险大小，该轴上取值越大，技术风险 越大，相应的技术创新水平越抵。不妨将 技术服务风险特征轴 (TSR 轴) 置于技术 风险特征轴 ( TR 轴) 的垂直下方, 且正 向向下, 该轴上的取值越大, 技术服务风 险越大。由于 TR 轴和 TSR 轴上的取值具 有关联性（技术创新风险越小，技术服务 
八、些过越小），它行沿各自的轴局时问上 下两端伸缩, 但伸缩幅度不一定相同, 这 与技术创新风险的水平和技术服务的能力 有关。

根据该四维风险特征模型，图 1 中四 面体的体积大小反映了新技术运营所面临 的整体风险大小，四面体体积越大，新技 术运营所面临的整体风险越大，因此，在 新技术运营的风险特征空间中，该四维风 险特征模型测度了新技术运营所面临的整 体风险及其动态变化过程。如果运营者根 据自身对风险的偏好对四类风险进行限 制, 则可以在风险特征空间的四个维度上 设置相应的临界值或阈值，随着四面体体 积的膨胀，新技术运营所面临的整体风险 水平随之加大, 风险的可容忍性逐渐降 低。一旦任一轴上的取值突破临界值，则 该新技术运营所面临的整体风险将由可容 忍的风险演变为 “不可容忍” 的风险。此 时, 可以认为新技术的运营将面临失败的 后果。

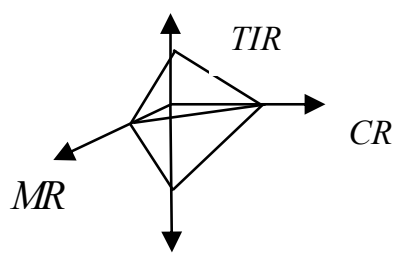

TSR

图 1：新技术运营的风险特征模型

\section{5. 结束语}

本文针对新技术运营的风险要素和风 险特征展开分析。依据内生性风险的内 涵, 内生性风险是与新技术运营的成败直 接相关的风险, 是新技术运营的主要风险 特征, 本文将其归纳为信用风险、技术创 新风险、市场风险和技术服务风险等四类 风险特征。进一步，根据上述四类风险特 征，构建了新技术运营的四维风险特征模 型。

需要指出的是, 该四类风险通常发生 在新技术运营的不同阶段，形成了新技术 运营的风险链。按照风险出现的时间顺
序，新技术运营自先面临的是信用风险, 在新技术的研发和整个运营阶段均面临技 术创新风险, 市场风险主要发生在新技术 运营的商业化阶段, 而技术服务风险则发 生在新技术的运营后期。微观层面上看, 由于四类风险刻画的风险目标不同, 运营 者可以根据对该四类风险的独立测度结果 对新技术运营所面临的整体风险进行识 别; 从宏观层面来看, 上述四类风险形成 了新技术运营的风险链。

\section{参考文献}

[1] 周宗放, 孔建会, 周一禁, 新技术运 营风险评估与综合管理，北京：经济 管理出版社，2015.12.

[2] 孔建会, 张凤英，周宗放，新技术运 营的风险特征与测度方法，西南财经 大学出版社，预计出版时间 2016 年 12 月。

[3] 陈林，周宗放. 从互联网在我国的发 展浅论新兴技术企业的信用风险 [J]. 价值工程，2005，4：123-126.

[4] Jianhui Kong, Fengying Zhang \& Zongfang Zhou, Fuzzy Comprehensive Evaluation of Service Agent Based on Large-scale Products of New Technology, Modern Economy, 2015, 6, 498-509.

[5] 李达等. 技术成熟度评价方法综述 [J]. 科学决策, 2012(11)：85-94.

[6] 周涛, 才兰萍, 张勇. 技术成熟度评价 方法应用现状及发展，计算机测量与 控制，2015,23（5）：1609-1611.

[7] Handerson, R., K.Clark. Architectural Innovation the Reconfiguration of Existing Product Technologies and the Failure of Established Firms[J]. Administrative Science Quarterly, 1990, 69(1):9-30.

[8] 周宗放, 陈林, 唐小我. 多维动态信 用评价的信用状态空间结构研究 [J], 系统工程理论与实践, 2007,4: 1-8.

[9] Jianhui Kong,Yimao Zhou,Hui Lai \& Zongfang Zhou,Analysis of Credit Sale Risk of Emerging Market Product, Information Technology and Quantitative Management, Procedia computer science, 2016. 